Family Medicine and Community Health

\title{
Focusing on the assets in our challenges: family medicine residency programme in Chiang Rai, Thailand
}

\author{
Daranee Intralawan, ${ }^{1}$ Hikari C Morikawa, ${ }^{2}$ Masahiro J Morikawa, ${ }^{3}$ \\ Ruangnipon Porruan ${ }^{1}$
}

To cite: Intralawan D, Morikawa HC, Morikawa MJ, et al. Focusing on the assets in our challenges: family medicine residency programme in Chiang Rai, Thailand. Fam Med Com Health 2020;8:e000500. doi:10.1136/fmch-2020-000500

Received 03 June 2020 Revised 01 July 2020 Accepted 27 July 2020

\section{Check for updates}

(C) Author(s) (or their employer(s)) 2020. Re-use permitted under CC BY-NC. No commercial re-use. See rights and permissions. Published by BMJ.

${ }^{1}$ Family Medicine, Chiangrai Prachanukroh Hospital, Chiang Rai, Thailand

${ }^{2}$ STEP Global, Charlottesville, Virginia, USA

${ }^{3}$ Family Medicine, University of Virginia School of Medicine, Charlottesville, Virginia, USA

Correspondence to Dr Daranee Intralawan; daranee.in@cpird.in.th

\section{BACKGROUND}

For more than 20 years, family medicine (FM) in Thailand is still looking for its place in our primary care healthcare system as an established specialty. Historically, primary care in Thailand was provided by the new graduates from the medical school. They were assigned to district hospitals as general practitioners (GPs) and were required to serve a 3-year period in various parts of the country. GPs have a primary medical qualification but have not undertaken a specialty in residency. They had to undergo 'on-the-job' training while functioning as the first-contact medical care providers in their community. Until the inception of FM residency, GPs could apply for formal medical subspecialty training (similar to the US residency programmes) and could return to teaching hospitals only after the completion of 3 years. The majority of them went back to teaching hospitals for further training and only a few of them chose to stay as GPs in the community due to the low recognition in the medical community, modest pay and heavy workload. As medical specialisation progressed in Thailand, the demand to standardise fragmented GP training into a new specialty residency programme became imminent. In response to the need, the Ministry of Public Health (MOPH) launched FM as an independent medical specialty in 1999 as a vehicle to deliver cost-efficient first-contact care to the entire population. The MOPH instructed universities to offer a 3-year residency programme, and currently, $38^{1}$ FM training programmes exist in Thailand. Eleven of them are based in universities and 27 are based in major teaching hospitals, including Chiang Rai Provincial Hospital. ${ }^{2}$

There are three pathways to become a family physician in Thailand, namely the hospital-based residency track, the in-service residency track and the retraining track.
The hospital-based residency is the one that was originally developed at universities. The MOPH modified the regulation and candidates are allowed to apply for the residency after a minimum of 1-year mandatory service for additional 3 years of residency training, mainly rotating through subspecialty and FM clinics. Only a limited number of programmes were available at initially due to a shortage of primary care educators. However, this track has not been able to produce a sufficient numbers of family physicians to meet the demand in the country, with most graduates choosing to become teaching staff at the universities.

The in-service residency track was developed by the MOPH in 2009. This track is designed to shorten the length of training by combining mandatory service and residency training. As there was a huge demand for primary care providers, this track boosts the number of family physicians in the busy district hospitals around the country ${ }^{3}$ and results in the majority of FM trainees being on this track. The residents can finish their mandatory service faster and apply directly to the hospitals in their preferred location rather than being randomly assigned throughout the country.

The retraining track is especially meant for existing GPs who have more then 5 years of experience. They could be certified as FM by continuing their medical education and by taking up the board examinations conducted by the Thai Royal College of Family Medicine (The College). The track has not attracted the expected number of candidates yet: GPs certified through this rigorous process do not benefit financially, as a busy GP practice is financially more beneficial based on productivity.

Chiang Rai Hospital is a tertiary care hospital that serves 1.2 million people in the 
Chiang Rai province in northern Thailand. The city shares borders with China, Laos and Myanmar and is located 490 miles from Bangkok, the capital city. The hospital serves as medical training centre with Chiang Mai University for the undergraduate medical students and postgraduate medical professionals in northern Thailand. In Chiang Rai Hospital, FM residency started 7 years ago as an in-service residency track with two full-time faculty members. In 2018, the hospital-based residency track was also implemented with 11 full-time faculty members. In 2019, we have two residents in the hospital-based track and nine residents in the in-service track.

\section{CHALLENGES IN ESTABLISHING FM TRAINING}

From the beginning, there have been obstacles to developing a which include the following:

1 . The large volume of patients (50-60 patients per provider per day ${ }^{4}$ ) at ambulatory care clinics across Thailand is a serious challenge to provide practice-based education both for learners and preceptors. According to the Constitution of the Kingdom of Thailand 2017, the MOPH mandates the promotion of FM as a principle vehicle of primary care and to achieve the ratio of one family physician to 10000 residents by $2027 .^{5}$ Balancing the unprecedented demand to increase the number of family physicians without compromising on the quality of training is difficult.

2. One of the foundations of clinical training is bedside clinical skills and we have therefore focused on bedside clinical instruction and precepting. ${ }^{6-8}$ Even though The College stipulates the curriculum and competency requirements, the actual implementation of the curriculum is largely dependent on local resources and support. The contents and teaching methods among different programmes vary significantly. The quality of education on the in-service track programmes is heavily dependent on local teaching faculty who are in various stages of their career and experience. The expectation from the residents is not met with delivery by local preceptors. ${ }^{9}$

3. Although skills in clinical and outcome research are incorporated as essential and mandatory for residents, the majority of teaching faculty members need further training in conducting research and providing guidance to the residents.

4. Many current teaching faculty members require further training in bedside clinical teaching to make the most of spared teaching opportunities. ${ }^{10}$ Faculty members on in-service track programmes often see teaching as an extra burden. In addition, it is hard to motivate faculty members to learn teaching skills when sufficient funding is not available. Faced with limited resources and mentors, junior faculty members who would like to provide care and to become educator are disappointed with the reality and end up changing their career to pursue already well-established subspecialties. This trend makes the remaining faculty mem- bers even busier and discourages improvement in the quality of training across the country.

5 . There is a continuing confusion regarding the distinction between GPs and family physicians both in medical and lay communities. The lack of the role of a family physician in the system has negatively affected the family doctors' motivation as well as the recruitment of residency candidates. ${ }^{11-13}$ Like many other countries struggling to establish primary care specialties, ${ }^{14}$ the triad of low recognition, limited support and overwhelming patient care does not help sustain teaching programmes and drives many to leave FM for other subspecialties or to non-teaching private practice.

\section{FOCUSING ON OUR ASSETS: CHIANG RAI PROGRAMME}

Despite the challenges, the authors believe the geographic, demographic and cultural uniqueness of the province in the development of a training programme helping residents become a competent primary care provider. The authors have focused on areas to improve educational efficiency, based on the high-functioning teaching practice design by the Association of American Medical Colleges ${ }^{15}$ and have come to focus on five areas where Chiang Rai Provincial Hospital can provide unique learning opportunities by incorporating various teaching methods to strengthen our residency programme.

\section{Wide spectrum of disease}

Chiang Rai is one of the fastest growing metropolitan areas in Thailand due to its proximity to China, our growing economic partner. Rapid urbanisation in rural lifestyle has brought a dynamic mixture of diseases: a variety of infectious diseases such as tuberculosis (TB), sexually transmitted infection, HIV/AIDS, and dengue fever, and a surge of non-communicable diseases such as hypertension, diabetes and lung diseases. ${ }^{16}$ This broad spectrum of diseases provide provides residents an extensive range of clinical opportunities for learning.

\section{Minority health and psychosocial issues}

Chiang Rai is known for its ethnic diversity. Numerous ethnic minorities in surrounding areas, often called mountain tribes, are untouched by development. There are pockets of medically underserved communities afflicted with diseases such as TB, childhood pneumonia and malnutrition, which are believed to have been caused as a result of poverty. The diverse and multicultural patients' background forces us to learn and become sensitive about the broader aspects of health issues, social determinants of health and health equity.

\section{Community outreach and public health}

Since we are providing care for the entire province, the residents have an opportunity to engage in public health interventions such as outbreak investigation, communitybased health education and immunisation campaigns. The exposure to population-based management is one 
of the essential skill sets for family physicians working in communities.

\section{Comprehensive care}

Chiang Rai is functioning as a referral hub for the surrounding areas including 18 district hospitals. Working closely with a regional network of primary care offers opportunities to learn and address numerous health issues in all primary, secondary and tertiary care settings. Since we administer both in-service and hospital-based tracks, residents from both programmes can learn from each other on the different scopes and views between communities and tertiary care centres.

\section{Monthly case workshop and multidisciplinary learning opportunities}

Every month, there is a 2-day workshop where each resident presents his/her 'case of the month'. The teaching faculty, residents, social workers and invited subspecialists discuss each case from psychosocial, medical and surgical aspects, reflecting patient-centred care. In 2016, we started our palliative care consult service in the provincial hospital, practising and teaching patient-centred care, team-based care, care coordination and continuity of care to our residents, and to residents from other disciplines.

The FM residency programme at Chiang Rai Hospital has been growing with the teaching collaboration. We anticipated a need for faculty development in our programme because we have recognised lack of adequate training in teaching and research. We have asked several foreign institutions to collaborate with us to mentor our faculty members. We started a faculty development programme 8 years ago with help from Case Western Reserve University (2012-2018) and the University of Virginia (since 2019), who have provided intensive faculty development workshops. In 2017, the Fulbright Scholar Program helped us implement workshops for in-service track faculty members in eight provinces in northern Thailand. As our number of core faculty members continues to grow, we have engaged in peer coaching among the faculty members through group self-reflection and discussions at faculty meetings. In the last few years, there have been several ongoing research projects and abstracts that were accepted for presentation at international conferences. Gradually, those outcomes are helping us become more confident in both research and teaching.

We believe the progress made by our department in practice and education helps us gain confidence and positive recognition from other subspecialties. At the Chiang Rai Hospital are determined to continue to play essential roles in strengthening FM as an independent specialty in the Thai healthcare system.

In summary, the authors have discussed the journey of establishing the FM residency programme in Chiang Rai, Thailand. So far, we have learnt the following lessons: (1) define our goal for training: a competent clinician as a first contact care provider in the community; (2) search for mentorship to seek specific help, both inside and outside the country, and strong guidance to build up a bedside teaching model model similar to that seen in foreign institutions; (3) implement a faculty development programme from the beginning; and (4) advocate for the role of FM to senior leadership at the hospital and the ministry and to engage them as our collaborators to improve overall care for our community. We hope our discussions will give some hints to establish FM where there are not enough preceptors.

Contributors All of the listed authors participated in planning and discussions of all the work. DI, HCM and MJM drafted the article. RP participated in revising the article.

Funding The authors have not declared a specific grant for this research from any funding agency in the public, commercial or not-for-profit sectors.

Competing interests None declared.

Patient consent for publication Not required.

Provenance and peer review Not commissioned; externally peer reviewed.

Open access This is an open access article distributed in accordance with the Creative Commons Attribution Non Commercial (CC BY-NC 4.0) license, which permits others to distribute, remix, adapt, build upon this work non-commercially, and license their derivative works on different terms, provided the original work is properly cited, appropriate credit is given, any changes made indicated, and the use is non-commercial. See: http://creativecommons.org/licenses/by-nc/4.0/.

\section{REFERENCES}

1 The general practitioner/family physician association of Thailand [Internet]. 20 years of family medicine in Thailand, 2019. Available: https://thaigpfm.org/2019/

2 The Royal College of Family Physicians of Thailand. List of the institutions offering Family Medicine Residency training [Internet] Available: https://thaifammed.org/training/

3 Rajbhandari R, McMahon DE, Rhatigan JJ, et al. The neglected hospital - the district hospital's central role in global health care delivery. N Engl J Med 2020;382:397-400.

4 Chiang Rai Provincial Health Office. Health Data Center Dashboard [Internet]. Available: http://61.19.32.29/hdc/main/index_pk.php

5 Office of Primary Health Care Support. Primary Health System Act B.E. 2562 [Internet]. Available: https://sites.google.com/site/prim arycarecluster2017/new/1-phrb-rabb-sukhphaph-pthm-phumi/phrbrabb-sukhphaph-pthm-phumi

6 Elder A. Clinical skills assessment in the twenty-first century. Med Clin North Am 2018;102:545-58.

7 Alpert JS. Will physicians stop performing physical examinations? Am J Med 2017;130:759-60.

8 Costanzo C, Verghese A. The physical examination as ritual. Med Clin North Am 2018;102:425-31.

9 Boonluksiri P, Tumviriyakul H, Arora R, et al. Community-based learning enhances doctor retention. Educ Health 2018;31:114-8.

10 Lumbiganon P, Chuenkongkaew W, Putthasri W. Education reform of health professionals for the 21st century: a situation analysis in Thailand. 1st edn. Bangkok: Health Professional Education Foundation, 2016: 82-90.

11 Kong $X$, Yang Y. The current status and challenges of community general practitioner system building in China. QJM 2015;108:89-91.

12 Liang D, Tang C-X. The specialty choice of medical students in China: a stated preference experiment. BMC Med Educ 2016;16:107.

13 Wang J, Zhao Q, Liu T, et al. Career orientation and its impact factors of general practitioners in Shanghai, China: a cross-sectional study. BMJ Open 2019;9:e021980.

$14 \mathrm{Li} \mathrm{X,} \mathrm{Lu} \mathrm{J,} \mathrm{Hu} \mathrm{S,} \mathrm{et} \mathrm{al.} \mathrm{The} \mathrm{primary} \mathrm{health-care} \mathrm{system} \mathrm{in} \mathrm{China.}$ Lancet 2017;390:2584-94.

15 Bodenheimer TG, Dube KR, et al. High-functioning primary care residency clinic. Washington DC: AAMC, 2016.

16 Angkurawaranon C, Jiraporncharoen W, Chenthanakij B, et al. Urbanization and non-communicable disease in Southeast Asia: a review of current evidence. Public Health 2014;128:886-95. 